\title{
Removal of drug and dye from aqueous solutions by graphene oxide: Adsorption studies and chemometrics methods
}

\author{
Jingjie Yang ${ }^{1}$, Siroos Shojaei $\mathbb{B D}^{2 \otimes}$ and Saeed Shojaei ${ }^{3}$
}

Pharmaceutical products and dyes are the main environmental pollutants in the effluent of textile, cosmetic, and pharmaceutical industries. Therefore, in this study, the central composite design (CCD) based on the response surface methodology (RSM) was used to investigate the operating parameters and determine the optimal conditions for the removal of enrofloxacin (ENF) and Rhodamine $\mathrm{B}(\mathrm{RhB})$ by graphene oxide (GO). The structure and morphology of GO were studied using scanning electron microscopes (SEM) and X-ray diffraction (XRD) techniques. Quadratic model was confirmed to describe each of the removal efficiency responses (\%R) a with high correlation coefficient $\left(R^{2}=0.9987\right.$ for ENF and $R^{2}=0.9999$ for RhB) $\left(R^{2}-A d j=0.9963\right.$ for ENF and $\mathrm{R}^{2}$-Adj $=0.9991$ for $\mathrm{RhB}$ ). In optimal conditions, $\mathrm{RhB}$ concentration of $10 \mathrm{mg} \mathrm{L}^{-1}$, adsorbent amount of $0.24 \mathrm{~g}$, sonication time of $23 \mathrm{~min}$, ENF concentration of $10 \mathrm{mg} \mathrm{L}^{-1}$, and $\mathrm{pH} \mathrm{7,} \mathrm{removal} \mathrm{rates} \mathrm{of} \mathrm{more} \mathrm{than} 92.5 \%$ were obtained for both analytes. Adsorption equilibrium was studied with Langmuir, Freundlich, Langmuir-Freundlich, Redlich-Peterson, Toth and Khan isotherm models. Equilibrium data were best fitted with the Langmuir-Freundlich isotherm model. Maximum adsorption capacity of ENF and RhB on GO were $45.035 \mathrm{mg} \mathrm{g}^{-1}$ and $107.230 \mathrm{mg} \mathrm{g}^{-1}$, respectively. The recyclability of GO was evaluated during the ENF and RhB adsorption process. The results showed that up to 4 cycles of adsorbent, the adsorption efficiency is reduced by a tiny amount. The present study showed that GO is highly effective in removing ENF and RhB from environmental water samples.

npj Clean Water (2022)5:5; https://doi.org/10.1038/s41545-022-00148-3

\section{INTRODUCTION}

Nowadays, the excessive use of pharmaceutical products and dyes due to the entry of some of these compounds into the environment has raised concerns worldwide. About $100,000-200,000$ tons of antibiotics and 7 million tons of dyes are used annually in the world ${ }^{1,2}$. Dyes are also used in various textile, food, paper, cosmetic and pharmaceutical industries, and about 10 to $15 \%$ of these dyes enter the aquatic ecosystem during the dyeing process ${ }^{3,4}$. In recent years, without any restrictions, these materials have been discharged continuously to the environment. Although their entry into aquatic environments may be low, their continuous navigation due to the cumulative effect can be considered a potential risk to aquatic ecosystems and their microorganisms ${ }^{5}$. Enrofloxacin (ENF) is a synthetic antibacterial drug from the carboxylic acid derivative of fluoroquinolone. Enrofloxacin is a collaborative group of antibiotics in the production and consumption worldwide that is used to treat various infectious diseases in humans and animals ${ }^{6}$. The presence of these drugs in the environment leads to the ecological toxicity and development of antibiotic-resistant pathogens that potentially threaten ecosystem function and human health ${ }^{7,8}$. Rhodamine $B(R h B)$ is a purple-pink seed pigment. RhB is used in various industries such as textile, printing, and leather industries ${ }^{9}$. It is also often used as a pigment routing in water to determine the direction and speed of transmission. The toxicity of this dye has been proven for humans and animals, and if swallowed, it irritates the eyes, skin, and respiratory system. Also, according to research, $\mathrm{RhB}$ is a carcinogen for living organisms, especially humans ${ }^{10}$. Accordingly, there is a need for an efficient system to remove these compounds from the aquatic environment. So far, various methods such as separation membrane, chemical oxidation, and biodegradation have been used to remove organic compounds ${ }^{11-16}$. Most of these techniques can produce secondary pollutants, or at least they are time-consuming. The adsorption process using cheap and available adsorbents is one of the most efficient, easiest, and most economical methods for removing dye and drug ${ }^{17,18}$. The advantages of this method are high efficiency, low operating costs, ease of use, and adaptation to the environment ${ }^{19,20}$. Since the adsorption performance is directly dependent on the quality and cost-effectiveness of the adsorbent, various attractions, including activated carbon $^{21}$, zeolite ${ }^{22}$, clay $^{23}$, and graphene oxide $(\mathrm{GO})^{24}$, have been studied in recent decades. Researchers have highly regarded the use of $\mathrm{GO}$ in adsorption processes. GO is considered a suitable inexpensive adsorbent due to its ease of access, ion exchangeability, and unique physicochemical properties ${ }^{25}$. GO is a two-dimensional material made of a single layer, with a hexagonal and crystalline structure, on the plates of oxygen groups. This substance has a high ability to interact with substances due to the presence of oxygen groups. It is also biocompatible and can be used as an adsorbent to remove a variety of contaminants ${ }^{26}$. In one study, Karimi-Maleh et al. (2020) prepared reduced graphene-iron oxide $\left(\mathrm{rGO}-\mathrm{Fe}_{3} \mathrm{O}_{4}\right)$. rGO$\mathrm{Fe}_{3} \mathrm{O}_{4}$ was used to remove phenazopyridine from wastewater samples. The results showed that in the best laboratory conditions and at $\mathrm{pH}=6$, phenazopyridine removal was more than $91 \%{ }^{27}$. Bezerra Araujo et al. (2019) used graphene oxide (GO) as an adsorbent to remove Methylene Blue (MB) dye from natural textile wastewater. Studies have shown that GO can remove approximately $85 \%$ turbidity and more than $60 \%$ of dye from an actual sample in $30 \mathrm{~min}$ to treat natural textile wastewater in $30 \mathrm{~min}$. The results showed that $\mathrm{GO}$ could be considered an excellent option for textile wastewater treatment ${ }^{28}$. In another study, Huang et al. ${ }^{29}$

\footnotetext{
${ }^{1}$ College of Environmental and Material Engineering, Yantai University, Yantai, Shandong 264005, China. ${ }^{2}$ Department of Chemistry, Faculty of Sciences, University of Sistan and Baluchestan, Zahedan 98135-674, Iran. ${ }^{3}$ Department of Arid and Mountainous Regions Reclamation, Faculty of Natural Resources, University of Tehran, Tehran, Iran.

凶email: shojaeisiroos@gmail.com
} 

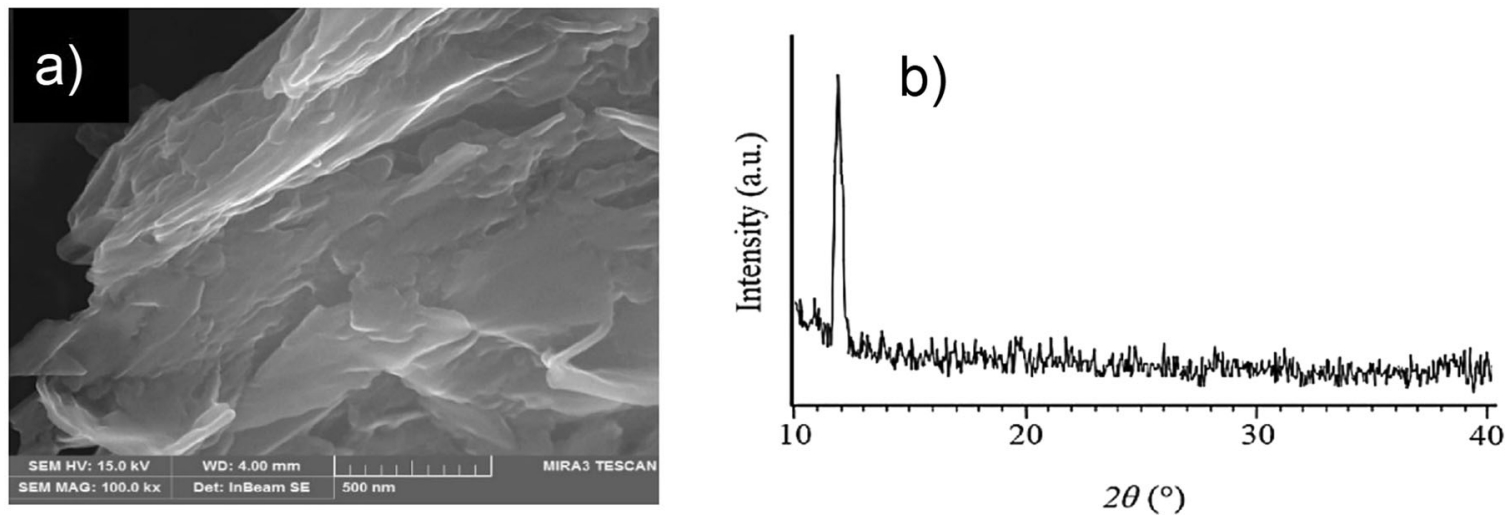

Fig. 1 Characterization of GO. a SEM image. b XRD pattern of GO.

\begin{tabular}{|c|c|c|c|c|c|c|c|c|c|c|c|}
\hline \multirow[t]{2}{*}{ Source } & \multicolumn{5}{|l|}{ ENF } & \multicolumn{6}{|l|}{ RhB } \\
\hline & Std. Dev. & R-Squared & $\begin{array}{l}\text { Adjusted } \\
\text { R-Squared }\end{array}$ & $\begin{array}{l}\text { Predicted } \\
\text { R-Squared }\end{array}$ & PRESS & Std. Dev. & R-Squared & $\begin{array}{l}\text { Adjusted } \\
\text { R-Squared }\end{array}$ & $\begin{array}{l}\text { Predicted } \\
\text { R-Squared }\end{array}$ & PRESS & Remarks \\
\hline Linear & 7.30 & 0.8247 & 0.7910 & 0.7396 & 2058.45 & 5.85 & 0.8312 & 0.7988 & 0.7788 & 1166.38 & --- \\
\hline $2 \mathrm{FI}$ & 7.69 & 0.8803 & 0.7680 & -0.1949 & 9444.49 & 7.29 & 0.8387 & 0.6874 & -0.8010 & 9496.29 & --- \\
\hline
\end{tabular}

synthesized $\mathrm{Cu} 2 \mathrm{O}$-reduced graphene $\left(\mathrm{Cu}_{2} \mathrm{O} / \mathrm{rGO}\right)$ nanocomposites through the in-situ wet-reduced method. This adsorbent was evaluated to remove rhodamine $B(R h B)$ solution under visible light. $\mathrm{Cu}_{2} \mathrm{O} / \mathrm{rGO}$ nanocomposites showed high efficiency so that the rate of RhB removal was more than $95 \%$. This study showed that $\mathrm{Cu}_{2} \mathrm{O} / \mathrm{rGO}$ nanocomposites could be successfully used to remove $\mathrm{RhB}$ from aqueous solutions ${ }^{29}$. In recent years, one of the most effective methods to remove pollutants from the water and wastewater is sonochemistry or ultrasound. The sonochemistry system can convert contaminants into by-products with less toxicity or harm to microorganisms ${ }^{30,31}$. Sonochemical reactions are caused by high-intensity sound radiation at frequencies that produce cavitation. Thus, cavitation acts as a concentrator of energy emitted by ultrasound into the micro-reactor, which acts as a hot spot. Ultrasound waves increase chemical and physical changes in a liquid medium through the production and subsequent destruction of cavitation bubbles. These bubbles are produced and disintegrated sequentially to produce the energy needed for chemical and mechanical effects. Therefore, using a sonochemistry system increases mass transfer, reduces time, and increases process efficiency, which can play a valuable role in removing contaminants ${ }^{32,33}$. Today, in most cases, response surface methodology (RSM) is used to optimize processes whose response is affected by more than two variables. RSM is a set of statistical and mathematical methods used to increase the efficiency of a process in which responses are affected by several variables ${ }^{34}$. RSM tries to find a way to estimate the interactions, quadratic effects, and even the local form of the studied response changes using a suitable experimental design. RSM has several benefits, including reducing the number of test steps, reducing time, reducing costs, and saving raw materials ${ }^{35}$. Therefore, as it was pointed out, this study aims to evaluate the efficiency of GO in removing ENF and RhB from environmental water samples. RSM is also used to increase process efficiency and optimize the factors affecting the removal rate.

\section{RESULTS AND DISCUSSION}

\section{Structural characterization of the graphene oxide (GO)}

The SEM image of the GO is shown in Fig. 1a. As can be seen in Fig. 1a, the prepared GO has sheets of different shapes and sizes, but their thickness is the same. Also, GO has a layered and laminated structure. Generally, such a shape is observed in GO in the form of layers ${ }^{36}$. Figure $1 \mathrm{~b}$ shows the XRD pattern from $\mathrm{GO}$ prepared by the Hammers method. In this model, a peak of $\mathrm{GO}$ at $2 \theta$ equal to 11.6 degrees indicates that $\mathrm{GO}$ has been synthesized $^{37}$. The average particle diameter of $15 \mathrm{~nm}$ was obtained according to the Scherrer equation and XRD data.

\section{Regression model equation establishment}

The RSM can be used for experimental modeling to investigate the relationship between experimental and predicted results. The range of test variables is coded according to CCD, and the ENF and $\mathrm{RhB}$ deletion values obtained are shown according to the test design performed in Supplementary Table 1. The predicted values showed that they have a reasonable correlation with the experimental values. The data were fitted to various linear, quadratic, and cubic models to obtain regression equations. As shown in Table 1, the quadratic model is the most suitable model for the adsorption process. The regression coefficients $\left(R^{2}>0.99\right.$ and $R^{2}$-adj $>0.99$ for both models) mentioned in Table 1 for the quadratic model indicate a well-fitting model.

Based on CCD, the experimental relationship between input variables and experimental results is provided by quadratic polynomial equations (Eqs. 1 and 2). The resulting equations 


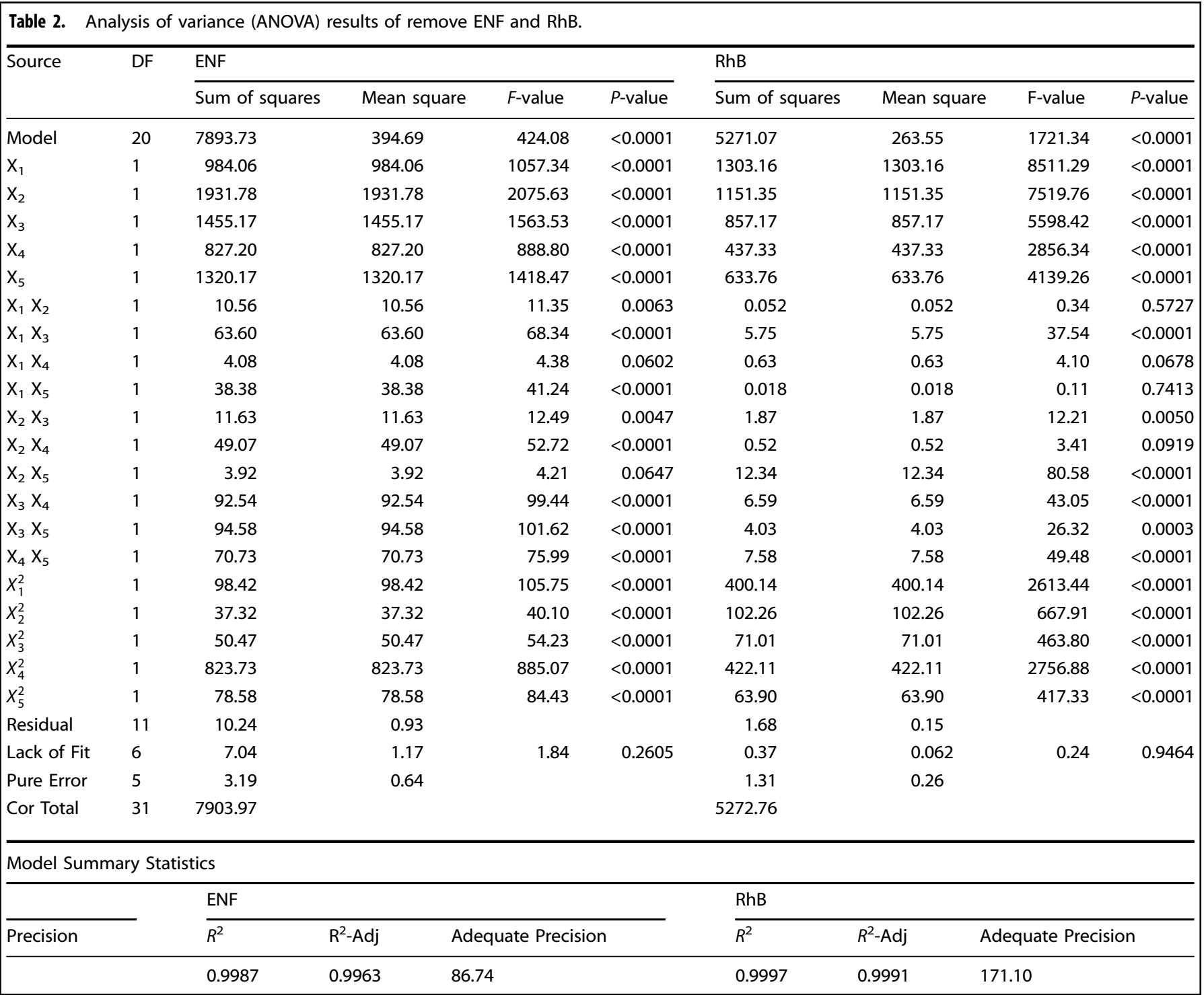

based on coded factors are:

$$
\begin{gathered}
\% \mathrm{R}(\mathrm{ENF})=+63.83+6.40 * X_{1}-8.97 * X_{2}-7.78 * X_{3}+5.87 * X_{4}+7.41 * X_{5}-0.81 \\
* X_{1} X_{2}-1.99 * X_{1} X_{3}-0.50 * X_{1} X_{4}+1.54 * X_{1} X_{5}+0.85 * X_{2} X_{3}+1.75 * X_{2} X_{4}-0.49 \\
* X_{2} X_{5}+2.40 * X_{3} X_{4}-2.43 * X_{3} X_{5}-2.1 * X_{4} X_{5}-1.83 * X_{1}^{2}-1.12 * X_{2}^{2}-1.31 * X_{3}^{2}-5.29 \\
* X_{4}^{2}-1.63 * X_{5}^{2}
\end{gathered}
$$

$\% \mathrm{R}(\mathrm{RhB})=+66.00+7.36 * X_{1}-6.92 * X_{2}-5.97 * X_{3}+4.26 * X_{4}+5.13 * X_{5}+0.05$

$* X_{1} X_{2}-0.59 * X_{1} X_{3}+0.19 * X_{1} X_{4}+0.03 * X_{1} X_{5}+0.34 * X_{2} X_{3}-0.18 * X_{2} X_{4}-0.87$ $* X_{2} X_{5}-0.64 * X_{3} X_{4}-0.50 * X_{3} X_{5}+0.68 * X_{4} X_{5}-3.69 * X_{1}^{2}-1.86 * X_{2}^{2}-1.55 * X_{3}^{2}-3.79$

$$
* X_{4}^{2}-1.47 * X_{5}^{2}
$$

In this equation, \%R represents the removal rate, $X_{1}, X_{2}, X_{3}, X_{4}$, and $X_{5}$ are the coded variables, representing the GO amount, ENF concentration, $\mathrm{RhB}$ concentration, $\mathrm{pH}$ of solution, and sonication time, respectively.

\section{Analysis of variance (ANOVA)}

The accuracy and importance of the selected model and the simultaneous effect of operational parameters in the process were evaluated by ANOVA analysis in Table 2. The results of ANOVA analysis showed that the proposed model has a statistically significant relationship with linear conditions concerning the one- way analysis of variance, which is $P \leq 0.05$. Also, the main operational parameters and the interaction of some parameters are simultaneously quite significant $(P \leq 0.05)$. The $p$-value level plays the most crucial role in determining whether the interaction of variables is significant or not. On the other hand, the F-value measures the deviation of the data from the average value $\mathrm{e}^{38,39}$. The $\mathrm{F}$ values for the ENF model and the RhB model were 424.08 and 1721.34 , respectively. This means that the variance of each variable is significant compared to the error variance and all the main parameters play an essential role in the response. Also, the adjusted correlation coefficient $\left(R^{2}\right.$-Adj) for ENF and RhB was equal to 0.9963 and 0.9991 respectively, indicating the statistical model's accuracy.

In order to validate the proposed model, various analyses were performed on it. As opposed to the data predicted by the model in Supplementary Fig. 1a, b, the graph of the experimental data shows that the values are uniformly and consistently aligned along a straight line and have a high correlation. In the statistical analysis of experimental data, it is necessary to check that the data have a normal distribution. In the normal distribution, the points related to the data are very close to each other and follow a straight line. The normal probability graph is shown in Supplementary Fig. 1c, d. According to these diagrams, since the errors 

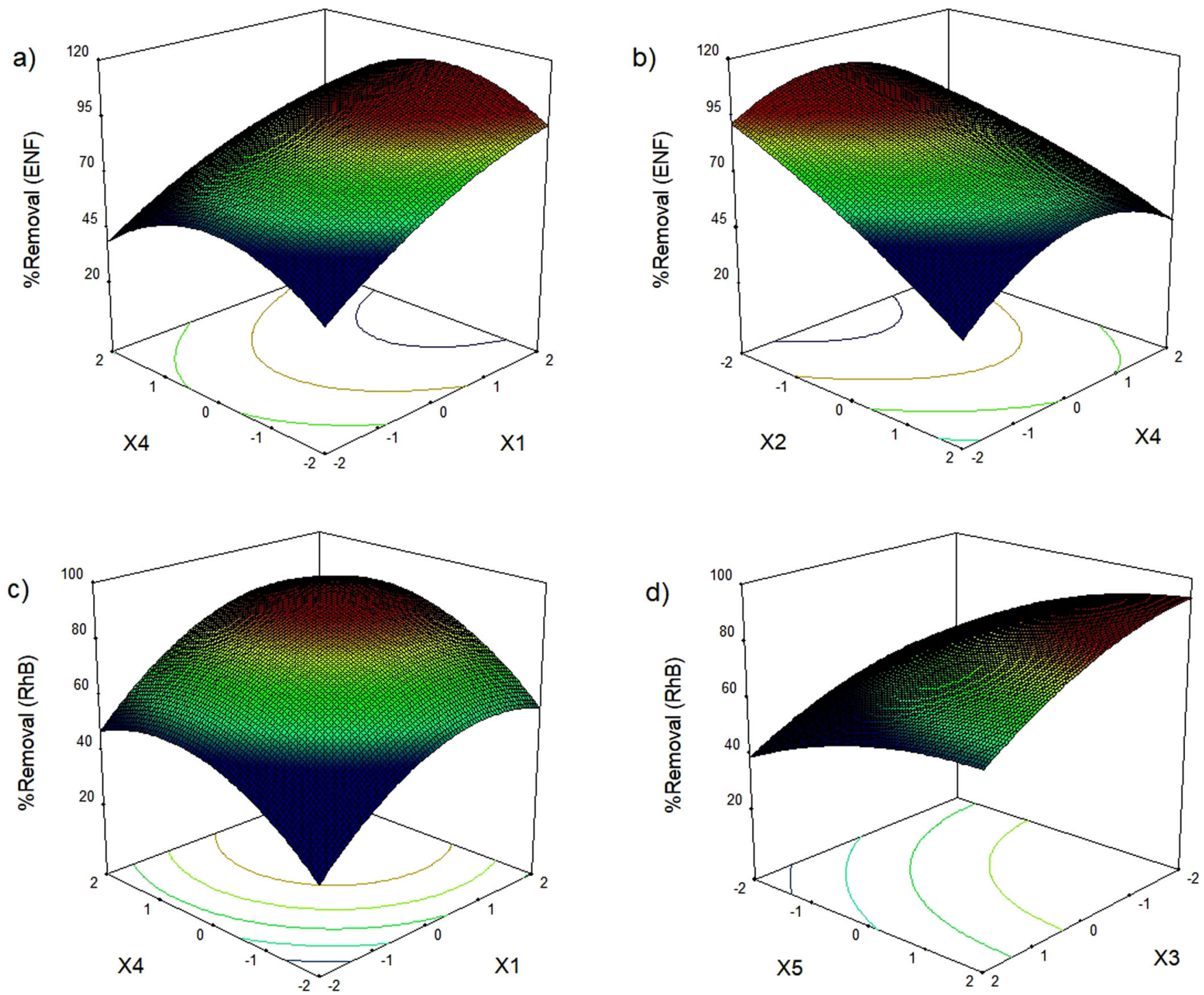

Fig. 2 The response surface plots. The influence of interaction term between variables onto removal of ENF (a, b) and RhB (c, d). $X_{1}$ : GO amount, $\mathrm{X}_{2}$ : ENF concentration, $\mathrm{X}_{3}$ : RhB concentration, $\mathrm{X}_{4}$ : $\mathrm{pH}$ of solution, and $\mathrm{X}_{5}$ : sonication time.

were normally distributed, the models were meaningful, and the predicted responses were consistent with the actual information ${ }^{40,41}$

\section{The effect of model parameters}

Figure $2 \mathrm{a}, \mathrm{b}$ show the effect of $\mathrm{pH}$, respectively, along with the effect of the amount of adsorbent and the ENF concentration on the ENF removal process. As can be seen, with increasing the amount of adsorbent, the removal efficiency increases dramatically. High dye/drug adsorption occurs in order to increase the amount of adsorbent due to the increase in the number of active sites, increase in the adsorbent surface, and the presence of a strong driving force ${ }^{42}$. Also, at low $\mathrm{pHs}$, the positive charge density at the adsorbent surface increases, and between the positive charge level of the adsorbent and the analyte molecules, the electrostatic attraction force decreases significantly. As a result, with decreasing electrostatic attraction, the access of drug and dye molecules to the active sites of adsorbent is reduced, and the removal rate is low ${ }^{43}$. According to the results, the highest amount of drug and dye removal was observed at $\mathrm{pH}$ 7. Figure $2 \mathrm{~d}$ shows the changes in the dye adsorption process by adsorption affected by $\mathrm{RhB}$ concentration and sonication time changes. The results show that as the RhB concentration decreases and the sonication time increases, the dye removal efficiency increases and these changes have a gentle trend regarding the reaction time. Increasing the contact time leads to an increase in the chance of dye molecules colliding with the adsorbent surface and the amount of dye removal efficiency increases. These results are in line with the findings of Duhan and Kaur (2021), who examined the removal of methylene blue using nano-structured polyaniline as an adsorbent ${ }^{44}$. On the one hand, since its active surface is constant for a certain amount of adsorbent, with increasing RhB concentration, the removal efficiency decreases due to the lack of active sites in the adsorbent surface. On the other hand, adsorbents have limited adsorption places, and when they are concentrated more, they are saturated faster, and as a result, there is a decline in efficiency. As dye concentration increases more, and dye adsorption on adsorbents is disrupted, the removal efficiency is declined. The results are in line with Shabaan et al.'s (2020) studies that removed cationic and anionic dyes using multiwall carbon nanotubes ${ }^{45}$. Pérez-Ramírez et al. (2019) also obtained similar results in a study to remove cationic and anionic dyes using one- and two-dimensional carbon nanomaterials as adsorbents ${ }^{46}$. 


\section{The effect of ultrasonic power}

Ultrasonic power is one of the effective parameters in cavitation activity and increasing the removal of pollutants. For this purpose, dye/drug solutions were placed under optimal conditions in an ultrasonic bath, and different powers $(10 \%, 30 \%, 50 \%, 70 \%$, and $90 \%$ ) with a frequency of $25 \mathrm{kHz}$. Figure 3 shows the effect of ultrasonic power on the removal of ENF and RhB. The removal efficiency of dye/drug in an aqueous solution depends on the ultrasonic power. Dye/drug removal percentage increases with increasing ultrasonic power. The increase in dye/drug removal and the increase in ultrasonic power can be explained by the number of active cavitation bubbles. As the ultrasonic power increases, the acoustic amplitude increases as the ultrasonic energy is transferred into the solution. The bubble pulses and collapses rapidly, and the number of cavities in the bubbles increases due to this amount of energy. As a result, high levels of hydroxyl radicals are released in the dye/drug solution. Similar results have been observed by Naddeo et al. (2020) in the study of the effect of ultrasonics on the removal of emerging contaminants (ECs) from environmental water samples. In this study, Naddeo et al. Stated that the removal efficiency of ECs increased with increasing ultrasonic power. The researchers attributed the increase in efficiency at low power levels to the effect of ultrasonic power on cavitation and the number of bubbles ${ }^{47}$. In addition, Özyonar et al. (2020) examined the removal of dispersing and reactive dyes by ultrasound-assisted electrocoagulation processes. They stated that the production of radical hydroxide in solution increases with increasing ultrasonic power. In addition, they reported that the decomposition efficiency decreases due to insufficient fall of cavitation bubbles and acoustic plate production with further increase in power ${ }^{48}$.

\section{Optimization}

Process optimization is of particular importance because of its direct impact on the result and the economic conditions of the process. Using numerical optimization, the response was

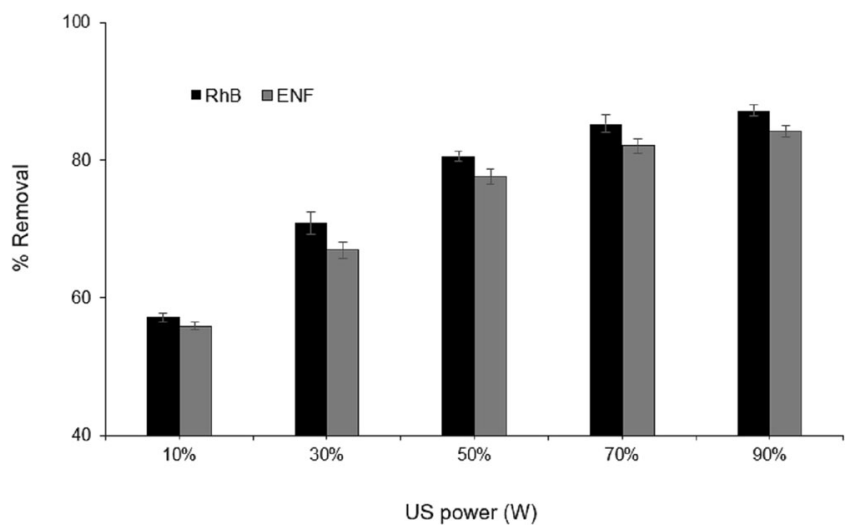

Fig. 3 The effect of ultrasonic power on the removal of ENF and RhB. Removal conditions: adsorbent amount: $0.24 \mathrm{~g}$, RhB concentration: $10 \mathrm{mg} \mathrm{L}^{-1}$, ENF concentration: $10 \mathrm{mg} \mathrm{L}^{-1}$, sonication time: $23 \mathrm{~min}$, and pH: 7. Error bars represent standard deviations. performed for five variables in the range of independent variables, the results of which are presented in Table 3. In this method, the factors that have a positive impact on the process are maximized, and at the same time, the factors that have a negative impact are minimized. Therefore, the target functions are set in such a way that the maximum removal percentage is achieved. Optimization was performed using the numerical optimization section in Design-Expert software. This optimization method has been performed in many other types of research and has valid results ${ }^{49,50}$. Since the optimization is based on the information obtained from the experiments and on the surface response model with $95 \%$ confidence, it could be implemented in this study.

\section{Adsorption isotherms study}

Isotherm is a mathematical (experimental or analytical) relation that concludes information about the properties of a solid surface, how the analyte is placed on the adsorbent (physical or chemical), and the presence or absence of interaction or competition between adsorbents for adsorption by establishing a relationship between the amount of analyte adsorbed by the adsorbent and the amount remaining in the solution in equilibrium. Therefore, different concentrations were selected for each of the contaminants, and the adsorption of these different concentrations under optimal conditions of other effective parameters following the proposed method was investigated. Then the desired isotherm was determined to describe how the adsorption concerning the value of the correlation coefficient for the linear state of the equations of conventional isotherms. Supplementary Table 2 shows the constant values of the isotherm and the correlation coefficient based on the linear equations of different isotherms for the absorption of ENF and RhB using GO. According to the values of $\mathrm{R}\left(0.228\right.$ for ENF and 0.109 for $\mathrm{RhB}$ ) and $\mathrm{q}_{\max }$ (45.035 for ENF and 107.230 for $\mathrm{RhB}$ ) calculated for both analytes, it can be concluded that the uptake of ENF and RhB by GO is in good agreement with the Langmuir-Freundlich isotherm.

\section{Kinetic study}

The adsorption rate and mechanism were investigated based on kinetic studies in the adsorption process. Therefore, different times were selected for each of the pollutants. Surface absorption was investigated under optimal conditions from other effective parameters under the proposed method. Then, the desired kinetic model was determined to investigate the kinetic and the mechanism of adsorption according to the correlation coefficient values for the linear mode of different kinetic equations. Supplementary Table 3 shows the constant kinetic values and the correlation coefficient based on the linear equations of varying kinetics for the adsorption of ENF and RhB using GO. The kinetic analysis was performed at four different times if the values for the other parameters were constant. Fitting of ENF and RhB adsorption kinetics models by GO shows the pseudo-secondorder kinetic model with a higher correlation coefficient $\left(R^{2}=\right.$ 0.9959 for ENF and $R^{2}=0.9991$ for RhB) compared to pseudo-firstorder, intraparticle diffusion, and Elovich models describe test data better. $q_{e}$ value obtained based on a pseudo-second-order

\begin{tabular}{|c|c|c|c|c|c|c|c|c|c|}
\hline Run & $x_{1}$ & $x_{2}$ & $x_{3}$ & $X_{4}$ & $X_{5}$ & Experimental & Predicted & Experimental & Predicted \\
\hline 2 & 0.8 & -1.0 & -1.0 & 0.5 & 1.6 & 98.16 & 97.43 & 91.47 & 91.02 \\
\hline 3 & 0.8 & -1.0 & -1.0 & 0.5 & 1.6 & 97.84 & 97.43 & 92.55 & 91.02 \\
\hline
\end{tabular}




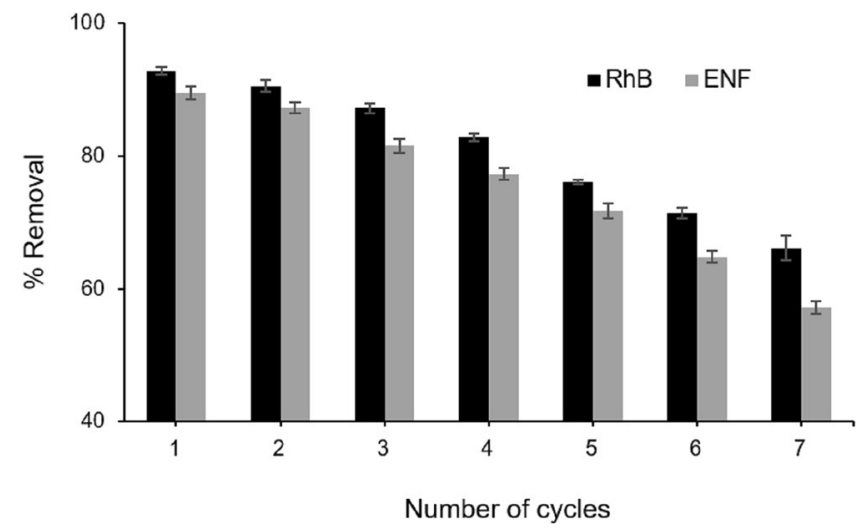

Fig. 4 Effect of regeneration cycles on the removal of ENF and RhB. Removal conditions: adsorbent amount: $0.24 \mathrm{~g}$, RhB concentration: $10 \mathrm{mg} \mathrm{L}^{-1}, \mathrm{ENF}$ concentration: $10 \mathrm{mg} \mathrm{L}^{-1}$, sonication time: $23 \mathrm{~min}$, and $\mathrm{pH}$ : 7. Error bars represent standard deviations.

kinetic model for ENF and RhB were $12426 \mathrm{mg} \mathrm{g}^{-1}$ and $12500 \mathrm{mg}$ $\mathrm{g}^{-1}$, respectively.

\section{Thermodynamic study}

The thermodynamic study was performed according to the proposed method by temperature changing process between $25^{\circ} \mathrm{C}$ and $40^{\circ} \mathrm{C}$. The enthalpy and entropy of the adsorption were calculated using the slope $\left(-\frac{\Delta \mathrm{H}^{\circ}}{R}\right)$ and the intercept $\left(\frac{\Delta \mathrm{S}^{\circ}}{R}\right)$ of the $\log _{c}$ diagrams versus $\left(\frac{1}{\mathrm{~T}}\right)$, respectively. The values of these variables are reported in Supplementary Table 4 . The results show that the values of $\Delta G^{\circ}$ obtained from the thermodynamic study are negative and indicate that the nature of ENF and RhB uptake is spontaneous by GO. A positive value of $\Delta \mathrm{H}^{\circ}$ also indicates that the adsorption process of ENF and RhB is endothermic. Also, the positive $\Delta S^{\circ}$ suggests a decrease in the degree of freedom of the adsorbed analytes at the $\mathrm{GO}$ adsorption sites.

\section{Reusability of spent adsorbent}

Reuse of used adsorbents is essential to protect the environment and reduce costs. For this purpose, adsorbent reuse was studied in successive cycles. As shown in Fig. 4, the adsorption efficiency gradually decreases with an increasing number of adsorbent reuse cycles. This decrease in contaminant removal efficiency can be related to blockage of pores, reduction of adsorbent sites, and loss of active adsorbent levels after each cycle ${ }^{51}$. As can be seen in Fig. 4, after four cycles of adsorbent application, the removal efficiencies of ENF and RhB were 83 and 78\%, respectively. These results show that $\mathrm{GO}$ can be used multiple times, and the cost of adsorbent preparation can be reduced.

\section{Interference studies}

In order to demonstrate the method's selectivity for the removal of ENF and RhB, the effect of several different ions on the removal efficiency was investigated. For this purpose, a certain amount of ENF and RhB along with disturbing ions in different concentrations were analyzed according to the method mentioned in the adsorption experiments section, and their effect on the removal efficiency of ENF and RhB was investigated. The results are shown in Supplementary Table 5. Anything that results in a $\pm 5 \%$ error in adsorption is known as a disturbing ion. It is observed that the cations and anions studied under optimal conditions do not interfere with the removal of ENF and RhB.

\begin{tabular}{|c|c|c|c|c|c|c|}
\hline \multirow[t]{2}{*}{ Analytes } & \multicolumn{2}{|l|}{ Tap water } & \multicolumn{2}{|l|}{ River water } & \multicolumn{2}{|c|}{ Hospital waste } \\
\hline & \%Removal & $\pm \mathrm{RSD}$ & \%Removal & $\pm \mathrm{RSD}$ & \%Removal & $\pm \mathrm{RSD}$ \\
\hline 1.98 & 88.69 & 1.57 & 91.82 & 2.65 & 95.86 & ENF \\
\hline 2.84 & 84.51 & 3.01 & 89.33 & 2.17 & 92.19 & $\mathrm{RhB}$ \\
\hline
\end{tabular}

\section{Simultaneous removal of ENF and RhB in actual samples}

In order to evaluate the efficiency of the method in the analysis of actual samples containing ENF and RhB in water samples such as tap water, river water, and hospital waste was used. In order to do so, instead of using distilled water, environmental water samples were used, and similar to the method mentioned in the adsorption experiments section, experiments were performed. Finally, the percentage of ENF and RhB removal was calculated by Eq. 3. The results of examining the actual sample are given in Table 4. The results of the analysis of different actual samples showed that there was no interference with the excipients in the actual textile wastewater samples.

\section{CONCLUSION}

This study showed the effectiveness of GO adsorbent in removing ENF and RhB from aqueous solutions. SEM and XRD analysis confirmed the nature and structure of GO. CCD-based RSM was used to examine the effective parameters of the process simultaneously. The results and statistical analysis showed that with increasing sonication time, increasing $\mathrm{pH}$, and increasing the amount of adsorbent, the efficiency of the removal process increases. Also, increasing the concentration reduces the removal efficiency. The analysis of variance (ANOVA) showed that the quadratic model was proportional and significant for the removal process. Under optimal conditions (RhB concentration $10 \mathrm{mg} \mathrm{L}^{-1}$, adsorbent amount $0.24 \mathrm{~g}$, sonication time $23 \mathrm{~min}$, ENF concentration $10 \mathrm{mg} \mathrm{L}^{-1}$, and $\mathrm{pH}$ 7), the removal efficiency was $98.16 \%$ for ENF and $92.55 \%$ for RhB. The adsorption of ENF and RhB onto GO followed pseudo-second-order kinetics and the equilibrium data fitted well with Langmuir-Freundlich isotherm. The maximum adsorption capacity $\left(\mathrm{q}_{\max }\right.$ ) was found to be $45.035 \mathrm{mg} \mathrm{g}^{-1}$ and $107.230 \mathrm{mg} \mathrm{g}^{-1}$ for ENF and RhB, respectively. The adsorbtion process onto the $\mathrm{GO}$ occurred spontaneously $\left(-\Delta \mathrm{G}^{\circ}\right)$, in an endothermic nature $\left(+\Delta \mathrm{H}^{\circ}\right)$, and with increased randomness $(+\Delta \mathrm{S}$ $\circ)$. The results of the reusability study showed that up to 4 reuse of the adsorbent, no significant change in its efficiency was observed. The method's efficiency for the analysis of environmental water samples containing ENF and RhB also showed that the above method could remove more than $84.51 \%$ of ENF and RhB from complex samples. Overall, the results showed that GO could be used as a high-availability, practical, and cost-effective adsorbent with optimized process operating conditions by CCD to simultaneously remove ENF and RhB from environmental water samples.

\section{METHODS}

\section{Materials and instruments}

Analytical grade reagents were used during the present study. ENF was provided by Sigma-Aldrich. RhB was bought at Merck. Stock solutions of drug $\left(1000 \mathrm{mg} \mathrm{L}^{-1}\right)$ and dye $\left(1000 \mathrm{mg} \mathrm{L}^{-1}\right)$ in double-distilled water were prepared. At different stages, working solutions were prepared and used by diluting these solutions. Sodium hydroxide $(0.1 \mathrm{M})$ and hydrochloric acid $(0.1 \mathrm{M})$ were also used to adjust the $\mathrm{pH}$ of the solutions during the experiments. The characteristics of drug and dye are listed in Supplementary Table 6. UV/Vis spectrophotometer (Model: 2120 UV plus, Optizen) was used to measure the concentration of drug and dye in solution. The $\mathrm{pH}$ of the solution was measured with a $\mathrm{pH}$ meter (Model: Hanna Instruments $\mathrm{HI}$ 
2210). An Ultrasonic Cleaner (Model: TI-H-10-MF2 Heated, Power consumption: $1000 \mathrm{~W}$, Ultrasonic power effective: $200 \mathrm{~W}$, Two operating frequencies: $25 \mathrm{kHz}$ and $45 \mathrm{kHz}$, Heating Power: $800 \mathrm{~W}$, Maximum filling volume: $8.6 \mathrm{~L}$ ) was used to investigate the effect of sound waves on the efficiency of the process. X-ray diffraction analysis (XRD) (Model: Siemens, D5000 using $\mathrm{Cu}$ Ka radiation) was used to identify the crystal phase of GO sheets. In order to study the morphology and characteristics of the surface a scanning electron microscope (SEM) (Model: KYKY-EM 3200) has been used. Statistical analysis of multivariate equations was performed using Design Expert statistical software (Version 10), and the effect of variables was determined.

\section{Preparation of graphene oxide (GO)}

In this method, the synthesis of graphene oxide (GO) as an adsorbent was performed by the Hummers method ${ }^{52,53}$. In order to prepare GO, $1 \mathrm{~g}$ of graphite powder and $0.5 \mathrm{~g}$ of sodium nitrate were poured into an Erlenmeyer flask. Then $23 \mathrm{~mL}$ of sulfuric acid was added to the Erlenmeyer flask and placed in an ice bath for $1 \mathrm{~h}$ on a shaker (1200 rpm). After $1 \mathrm{~h}, 3 \mathrm{~g}$ of potassium permanganate was slowly added to the contents of the Erlenmeyer flask. After homogenizing the solution, the Erlenmeyer flask was removed from the ice bath and stirred at room temperature for $12 \mathrm{~h}$ at $1200 \mathrm{rpm}$ for $46 \mathrm{~min}$. In the end, $100 \mathrm{~mL}$ of distilled water and $10 \mathrm{~mL}$ of hydrogen peroxide were added to the solution (to decompose metal ions) The GO was then washed with $250 \mathrm{~mL}$ of $5 \%$ hydrochloric acid and then several times with distilled water. Finally, the supplied $\mathrm{GO}$ was placed inside the oven at $50^{\circ} \mathrm{C}$ for $72 \mathrm{~h}$ to dry.

\section{Adsorption experiments}

In order to investigate the uptake of ENF and RhB by GO, specific amounts of $\mathrm{GO}(0.1-0.3 \mathrm{~g})$ were poured into $250 \mathrm{~mL}$ Erlenmeyer flask according to the experimental design. This Erlenmeyer flask already had $50 \mathrm{~mL}$ of the specified concentration of ENF $\left(5-25 \mathrm{mg} \mathrm{L}^{-1}\right)$ and $50 \mathrm{~mL}$ of the specified concentration of $\mathrm{RhB}\left(5-25 \mathrm{mg} \mathrm{L}^{-1}\right)$. The $\mathrm{pH}$ of the solution was adjusted in the desired range (2-10). Erlenmeyer flask and its contents were placed in an ultrasonic bath at the time specified by the software (5-25 min). Also, after this time, the solution was centrifuged $(3000 \mathrm{rpm})$ for $5 \mathrm{~min}$. Finally the upper part of the solution was sampled. The adsorption of the solutions was read using the UV/Vis spectrophotometer at $270 \mathrm{~nm}$ and $555 \mathrm{~nm}$ for ENF and RhB, respectively. The removal efficiency of ENF and RhB from Eq. 3 was determined.

$\% \mathrm{R}=\frac{\mathrm{C}_{\mathrm{o}}-\mathrm{C}_{\mathrm{e}}}{\mathrm{C}_{\mathrm{o}}} \times 100$

where $C_{o}\left(\mathrm{mg} \mathrm{L}^{-1}\right)$ and $C_{e}\left(\mathrm{mg} \mathrm{L}^{-1}\right)$ are the initial and equilibrium concentrations of the drug or dye in solution, respectively. Also, adsorption equilibrium capacity $\left(q_{e}\right)$ was obtained via the Eq. 4

$\mathrm{q}_{e}=\frac{V\left(C_{0}-C_{e}\right)}{m}$

In this Equation, $V(\mathrm{~L})$ is the volume of the analyte solution, and $m(\mathrm{~g})$ is the adsorbent mass.

\section{Adsorption isotherms}

Equilibrium adsorption isotherm models are essential requirements for the design of adsorption systems and the adsorbent-absorbed interactions that provide the necessary information about the adsorbent capacity. Isotherm models are plotted as the number of milligrams absorbed per gram of adsorbent versus the equilibrium concentration of adsorbent ${ }^{54}$ So, the experimental data were analyzed by the Langmuir, Freundlich, Langmuir-Freundlich, Redlich-Peterson, Toth, and Khan models.

\section{Langmuir isotherm}

The Langmuir isotherm is one of the most prominent isotherm models in the literature. It describes the nonlinear equilibrium between the amoun of adsorbed analyte and its excess amount in solution at a constant temperature. The Langmuir isotherm shows that adsorbed analyte increases with increasing concentration until the adsorbent surface becomes saturated. In other words, adsorption increases with increasing analyte concentration as long as available sites are available. However, a further increase in analyte concentration does not increase the amount of analyte adsorption on the adsorbent when these sites are occupied. The
Langmuir isotherm is described as Eq. 5:

$\mathrm{q}_{e}=\frac{K_{L} \times C_{e} \times \mathrm{q}_{\max }}{1+\left(K_{L} \times C_{e}\right)}$

where, $q_{e}\left(\mathrm{mg} \mathrm{g}^{-1}\right)$ is the adsorbed ions per unit mass of adsorbent at equilibrium, $c_{e}\left(\mathrm{mg} \mathrm{L}^{-1}\right)$ is the equilibrium concentration of the species, $q_{\max }\left(\mathrm{mg} \mathrm{g}^{-1}\right)$ is the maximum adsorption capacity, and $k_{L}\left(\mathrm{~L} \mathrm{mg}^{-1}\right)$ is the Langmuir coefficient related to the binding energy.

\section{Freundlich isotherm}

The Freundlich isotherm model is the main known relation that describes the adsorption process. This model is for multi-layer absorption. This isotherm is also used to adsorption on heterogeneous surfaces by interacting between adsorbed molecules. The application of the Freundlich isotherm also suggests that the adsorption energy decreases exponentially during the completion of the adsorption sites on the adsorbent surface. The Freundlich isotherm is expressed as Eq. 6.

$\mathrm{q}_{e}=\mathrm{K} \times \mathrm{C}_{\mathrm{e}}^{1 / \mathrm{n}}$

where, $q_{e}\left(\mathrm{mg} \mathrm{g}^{-1}\right)$ is the adsorbed ions per unit mass of adsorbent at equilibrium, $n$ is the absorption intensity, $C_{e}\left(\mathrm{mg} \mathrm{L}^{-1}\right)$ is the equilibrium concentration, and $K$ is the constant associated with the adsorption capacity at a unit concentration $\left(\mathrm{mg} \mathrm{g}^{-1}\right)\left(\mathrm{L} \mathrm{mg}^{-1}\right)^{1 / n}$.

\section{Langmuir-Freundlich isotherm}

The Freundlich isotherm considers the surface heterogeneity, and the Langmuir isotherm justifies the experimental surface adsorption process. The Langmuir-Freundlich isotherm is presented as Eq. 7 from integrating these two isotherms.

$\mathrm{q}_{e}=\frac{\left(\mathrm{K} \times \mathrm{C}_{e}\right)^{\mathrm{n}} \times \mathrm{q}_{\max }}{1+\left(\mathrm{K} \times \mathrm{C}_{\mathrm{e}}\right)^{\mathrm{n}}}$

where, $q_{e}\left(\mathrm{mg} \mathrm{g}^{-1}\right)$ is the adsorbed ions per unit mass of adsorbent at equilibrium, $n$ is the non-uniformity factor of the surface, $C_{e}\left(\mathrm{mg} \mathrm{L}^{-1}\right)$ is the equilibrium concentration, $K$ is the Langmuir- Freundlich constant, and $q_{\max }\left(\mathrm{mg} \mathrm{g}^{-1}\right)$ is the maximum theoretical concentration of the adsorbed single-layer in the adsorbent.

\section{Redlich-Peterson isotherm}

The Redlich-Peterson isotherm is a combination of the Langmuir and Freundlich isotherms differently, and the parameters of both isotherms are considered. The Redlich-Peterson isotherm is defined in Eq. 8.

$\mathrm{q}_{e}=\frac{\mathrm{K} \times \mathrm{C}_{e} \times \mathrm{q}_{\max }}{1+\left(\mathrm{K} \times \mathrm{C}_{e}\right)^{\mathrm{n}}}$

where, $q_{e}\left(\mathrm{mg} \mathrm{g}^{-1}\right)$ is the adsorbed ions per unit mass of adsorbent at equilibrium, $n$ is the non-uniformity factor of the surface, $C_{e}\left(\mathrm{mg} \mathrm{L}^{-1}\right)$ is the equilibrium concentration, $K$ is the constant of Redlich-Peterson, and $q_{\max }$ $\left(\mathrm{mg} \mathrm{g}^{-1}\right)$ is the maximum adsorption capacity.

\section{Toth isotherm}

The Toth isotherm is defined for adsorption on a non-uniform surface without lateral interactions, and asymmetric energy distribution is related to low absorption energy. The Toth isotherm is defined in Eq. 9:

$\mathrm{q}_{e}=\frac{\mathrm{K} \times \mathrm{C} \times \mathrm{q}_{\max }}{\left(1+(\mathrm{K} \times \mathrm{C})^{\mathrm{n}}\right)^{1 / \mathrm{n}}}$

In this equation, $q_{e}\left(\mathrm{mg} \mathrm{g}^{-1}\right)$ is the adsorbed ions per unit mass of adsorbent at equilibrium, $n$ is the non-uniformity factor of the surface, $C_{e}$ ( $\mathrm{mg} \mathrm{L}^{-1}$ ) is the equilibrium concentration, $K$ is constant Toth, and $q_{\max }$ (mg $\mathrm{g}^{-1}$ ) is the maximum adsorption capacity.

\section{Khan isotherm}

GO proposed the khan isotherm investigate the adsorption of the desired analytes. The Khan isotherm equation can show the properties of the Langmuir and Freundlich isotherms. For example, the Langmuir equation is obtained if 1 is placed in the equation instead of $n$. The Freundlich equation is also concluded if $\left(K \times C_{e}\right)$ is much larger than the unit. The Khan 
isotherm is defined in Eq. 10:

$\mathrm{q}_{e}=\frac{\mathrm{K} \times \mathrm{C}_{e} \times \mathrm{q}_{\max }}{\left(1+\left(\mathrm{K} \times \mathrm{C}_{\mathrm{e}}\right)\right)^{\mathrm{n}}}$

where, $q_{e}\left(\mathrm{mg} \mathrm{g}^{-1}\right)$ is the adsorbed ions per unit mass of adsorbent at equilibrium, $n$ is the non-uniformity factor of the surface, $C_{e}\left(\mathrm{mg} \mathrm{L}^{-1}\right)$ is the equilibrium concentration, $K$ is Khan constant, and $q_{\max }\left(\mathrm{mg} \mathrm{g}^{-1}\right)$ is the maximum adsorption capacity.

\section{Kinetic experiments}

In adsorption reactions, information about the final state of a system, such as adsorbent capacity and reaction equilibrium constant, can be obtained by using thermodynamic data. However, the study of adsorption kinetics provides information on the reaction path, mechanism of adsorption and adsorption rate ${ }^{55}$. Adsorption and desorption are time-dependent processes. Awareness of adsorption rate and desorption rate is required to design and evaluate the adsorption system. To justify the mechanism, a series of adsorption processes on removing pollutants, pseudo-first-order, pseudo-second-order, Elovich, and intraparticle diffusion models, were investigated.

\section{Pseudo first-order kinetics}

The first velocity equation for adsorption in a solid-liquid system based on adsorbent capacity was proposed in early 1898 by Lagergren as Eq. $11^{56}$ :

$\frac{d q_{t}}{d t}=k_{1}\left(q_{e}-q_{t}\right)$

Equation 12 is concluded by integrating Eq. 11 and creating boundary conditions $\left(t=0, q_{t}=0\right)$ and $\left(t=t, q_{t}=q_{t}\right)$ :

$\log \left(q_{e}-q_{t}\right)=\log \left(q_{e}\right)-\frac{k_{1}}{2.303} t$

where, $q_{e}\left(\mathrm{mg} \mathrm{g}^{-1}\right)$ and $q_{t}\left(\mathrm{mg} \mathrm{g}^{-1}\right)$ are the amount of analyte absorbed in equilibrium and at time $t$, respectively. $k_{1}\left(\mathrm{~min}^{-1}\right)$ is the pseudo-first order rate constant. $k_{1}$ and $q_{t}$ can can be determined from the slope and intercept of the plot $\log \left(q_{e}-q_{t}\right)$ versus of time.

\section{Pseudo second-order kinetics}

The pseudo-second-order kinetic model was proposed experimentally for the ion exchange process in 1984 by Blanchard ${ }^{57}$. Hu and McKay (1999) then used this equation for the adsorption process ${ }^{58}$. The pseudo-secondorder kinetic equation for an adsorption system is described as Eq. 13.

$\frac{d q_{t}}{d t}=k_{2}\left(q_{e}-q_{t}\right)^{2}$

Equation 14 was created by integrating the above equation and creating boundary conditions $t=0, q_{t}=0$ and $t=\mathrm{t}, q_{t}=q_{t}$ :

$\frac{\mathrm{t}}{\mathrm{q}_{\mathrm{t}}}=\frac{1}{\mathrm{k}_{2} \mathrm{q}_{\mathrm{e}}^{2}}+\frac{\mathrm{t}}{\mathrm{q}_{\mathrm{e}}}$

where, $q_{t}\left(\mathrm{mg} \mathrm{g}^{-1}\right)$ is the adsorption capacity at time $\mathrm{t}, q_{e}\left(\mathrm{mg} \mathrm{g}^{-1}\right)$ is the adsorption capacity at equilibrium time, $\mathrm{t}(\mathrm{min})$ is time, and $k_{2}\left(\mathrm{~g} \mathrm{mg}^{-1}\right.$ $\min ^{-1}$ ) is pseudo-second-order rate constant. $k_{2}$ and $q_{e}$ can be obtained from the intercept and the slope of the equation, respectively, by drawing a linear plot $\frac{t}{q_{t}}$ in terms of time.

\section{Intraparticle diffusion model}

The adsorption process is transferred in two stages, i.e., the adsorbed molecule is transferred from the solution to the adsorbent surface. It penetrates from the adsorbent surface into it in the next step. The second stage is a slow process in this kinetics, which determines the rate. The linear form of intraparticle kinetics is expressed as Eq. 15:

$a_{e}=k_{\text {diff }} 0^{0.5}+\mathrm{C}$

where, $k_{\text {diff }}\left(\mathrm{mg} \mathrm{g}^{-1} \mathrm{~min}^{1 / 2}\right.$ ) is the intra-particle penetration rate constant, $q_{t}\left(\mathrm{mg} \mathrm{g}^{-1}\right)$ is the adsorption capacity in time, $t(\mathrm{~min})$ is time, and $C$ is the thickness of the boundary layer. Multiple lines are obtained using the $q_{t}$ diagram relative to $t^{1 / 2}$, which in this case indicates that the infiltration process is multi-stage. The slope and the intercept can be calculated directly from this line.

\section{Elovich model}

The Elovich model has been widely proposed to explain the adsorption kinetics and chemical adsorption of gases on solid adsorbents. Elovich model explains the adsorption kinetics of ion exchange. In other words, this is the best process kinetic expression when the adsorption mechanism is ion exchange. Elovich model is in the form of Eq. 16.

$\frac{\mathrm{dq}}{\mathrm{dt}}=\mathrm{ae}^{-\beta q_{\mathrm{t}}}$

Equation 17 is obtained from Eq. 16 assuming $a \beta t>>1$ and integration using boundary conditions $\left(t=0, q_{t}=0\right)$ and $\left(t=t, q_{t}=q_{t}\right)$ :

$q_{t}=\frac{1}{\beta} \ln (\alpha \beta)+\frac{1}{\beta} \ln t$

where, $a\left(\mathrm{mg} \mathrm{g}^{-1} \mathrm{~min}^{-1}\right)$ is the initial adsorption rate constant, $\beta$ ( $\mathrm{mg} \mathrm{g}^{-1}$ ) is a parameter related to the amount of surface coating and activation energy for chemical adsorption, $q_{t}\left(\mathrm{mg} \mathrm{g}^{-1}\right)$ is the adsorption capacity at time and $t(\min )$ is time. $\frac{1}{\beta}$ and $\ln (\alpha \beta) \frac{1}{\beta}$ can be obtained from the slope and intercept, respectively, by plotting the linear graph $q_{t}$ versus Int.

\section{Thermodynamic study}

In thermodynamics mainly relies on the initial and final state of the system. So, the thermodynamic parameters of the system can be obtained by having initial and final values. Analysis of thermodynamic studies reveals the reaction of entropy changes $\left(\Delta \mathrm{S}^{\circ}\right)$, enthalpy changes $\left(\Delta \mathrm{H}^{\circ}\right)$ and free energy changes $\left(\Delta \mathrm{G}^{\circ}\right)$, whether it is spontaneous or non-spontaneous, and whether it is endothermic or exothermic reactions. The values of thermodynamic parameters, including $\Delta \mathrm{S}^{\circ}, \Delta \mathrm{G}^{\circ}$, and $\Delta \mathrm{H}^{\circ}$, are obtained using Eqs. 18-21:

$\mathrm{K}_{\mathrm{c}}=\frac{C_{s}}{C_{e}}$

$\Delta \mathrm{G}^{\circ}=-\mathrm{RTInK}_{\mathrm{c}}$

$\Delta \mathrm{G}^{\circ}=\Delta \mathrm{H}-\mathrm{T} \Delta \mathrm{S}^{\circ}$

$\log \mathrm{K}_{\mathrm{c}}=\frac{\Delta \mathrm{S}^{\circ}}{2.303 R}-\frac{\Delta \mathrm{H}^{\circ}}{2.303 R}\left(\frac{1}{T}\right)$

where, $K_{c}$ is the equilibrium constant, $C s\left(\mathrm{mg} \mathrm{L}^{-1}\right)$ is the adsorbed concentration of the analyte on the solid surface, $C_{c}\left(\mathrm{mg} \mathrm{L}^{-1}\right)$ is the residual concentration of analyte on the solid surface, $\Delta \mathrm{G}^{\circ}$ is free energy changes, $R$ is the gas constant $\left(8.314 \mathrm{~J} \mathrm{~mol}^{-1} \mathrm{~K}^{-1}\right)$ and $T(\mathrm{~K})$ is the absolute temperature. The values $\Delta \mathrm{H}^{\circ}$ and $\Delta \mathrm{S}^{\circ}$ are obtained from the slope and latitude from the origin of the curve $\ln K_{d}$ versus $\frac{1}{T}$. According to the results, the values of $\Delta G^{\circ}$ indicate that the process is spontaneous if it is negative. Positive values of $\Delta \mathrm{H}^{\circ}$ suggest that it is endothermic and positive values of $\Delta S^{\circ}$ show an increase in irregularity in the adsorbent surface for the desired contaminant.

\section{Modeling and optimization using RSM}

In this study, CCD based on RSM was used to optimize, determine the effect of independent variables and the simultaneous interaction between these variables on response performance (removal efficiency ENF and RhB) Design Expert software. In this design, $X_{1}$ (GO amount), $X_{2}$ (ENF concentration), $X_{3}$ (RhB concentration), $X_{4}$ ( $\mathrm{pH}$ of solution), and $X_{5}$ (sonication time) were the five variables affecting the response. Then, based on the number of variables and their levels, the experimental design table was determined. Different states in terms of solution $\mathrm{pH}, \mathrm{GO}$ amount, sonication time, ENF concentration, and RhB concentration were determined, and experiments were performed by considering the inserted codes. All measurements were repeated three times. The design includes 16 factorial design points, 10 axial points, 6 central points, and a total of 32 experiments. Central points are a method for estimating and evaluating experimental error and measuring the lack of Fit. The response functions (Y) are a function of the coded variables and are represented by quadratic polynomials in Eq. 22:

$Y=b_{0}+\sum_{i=1}^{4} b_{i} x_{i}+\sum_{i=1}^{4} b_{i i} x_{i}^{2}+\sum_{i=1}^{3} \sum_{j=i+1}^{4} b_{i j} x_{i} x_{j}$

The coefficients of the polynomial model are expressed as $b_{0}$ (fixed expression), $b_{i}$ (linear effects), $b_{i i}$ (quadratic effects), and $b_{i j}$ (interaction 
effects). The significance of each sentence in the regression equation was investigated. RSM statistical design and analysis of variance were used to compare means, and the results were considered significant with a probability of $\mathrm{P} \leq 0.05$.

\section{DATA AVAILABILITY}

All data generated or analysed during this study are included in this article.

Received: 23 July 2021; Accepted: 28 January 2022;

Published online: 02 March 2022

\section{REFERENCES}

1. Bhagat, C., Kumar, M., Tyagi, V. K. \& Mohapatra, P. K. Proclivities for prevalence and treatment of antibiotics in the ambient water: A review. npj Clean. Water $\mathbf{3}$ 1-18 (2020).

2. Gui, W. et al. A two-step strategy for high-efficiency fluorescent dye removal from wastewater. npj Clean. Water 2, 1-9 (2019).

3. Ali, S. S. et al. Construction of a novel cold-adapted oleaginous yeast consortium valued for textile azo dye wastewater processing and biorefinery. Fuel $\mathbf{2 8 5}$ 119050 (2021).

4. Krasucka, P. et al. Engineered biochar-A sustainable solution for the removal of antibiotics from water. Chem. Eng. J. 405, 126926 (2021).

5. Maged, A., Iqbal, J., Kharbish, S., Ismael, I. S. \& Bhatnagar, A. Tuning tetracycline removal from aqueous solution onto activated 2: 1 layered clay mineral: Characterization, sorption and mechanistic studies. J. Hazard. Mater. 384, 121320 (2020)

6. Rusch, M., Spielmeyer, A., Zorn, H. \& Hamscher, G. Degradation and transformation of fluoroquinolones by microorganisms with special emphasis on ciprofloxacin. Appl. Microbiol. Biotechnol. 103, 6933-6948 (2019).

7. De Smet, J. et al. The impact of therapeutic-dose induced intestinal enrofloxacin concentrations in healthy pigs on fecal Escherichia coli populations. BMC Vet. Res. 16, 1-12 (2020).

8. Li, J. et al. The effects of different enrofloxacin dosages on clinical efficacy and resistance development in chickens experimentally infected with Salmonella Typhimurium. Sci. Rep. 7, 1-12 (2017).

9. Al-Saidi, H. M., Abdel-Fadeel, M. A. \& Alharthi, S. S. Preconcentration and ultrasensitive spectrophotometric estimation of tungsten in soils using polyurethane foam in the presence of rhodamine B: Kinetic and thermodynamic studies, and designing a simple automated preconcentration system. J. Saudi Chem. Soc. $\mathbf{2 5}$ 101301 (2021).

10. Cui, H., Dong, S., Wang, K., Luan, M. \& Huang, T. Synthesis of a novel Type-II In2S3/ $\mathrm{Bi}_{2} \mathrm{MoO}_{6}$ heterojunction photocatalyst: Excellent photocatalytic performance and degradation mechanism for Rhodamine B. Sep. Purif. Technol. 255, 117758 (2021).

11. Zhang, S., Jiang, J. Q. \& Petri, M. Preliminarily comparative performance of removing bisphenol-S by ferrate oxidation and zonation.npj Clean Water 4, 1-7 (2021).

12. Liu, Y. et al. A multifunctional hierarchical porous $\mathrm{SiO}_{2} / \mathrm{GO}$ membrane for high efficiency oil/water separation and dye removal. Carbon 160, 88-97 (2020).

13. Mi, Y. F., Xu, G., Guo, Y. S., Wu, B. \& An, Q. F. Development of antifouling nanofiltration membrane with zwitterionic functionalized monomer for efficient dye/ salt selective separation. J. Membr. Sci. 601, 117795 (2020).

14. Pirsaheb, M., Hossaini, H. \& Janjani, H. Reclamation of hospital secondary treatment effluent by sulfate radicals based-advanced oxidation processes (SR-AOPs) for removal of antibiotics. Microchem. J. 153, 104430 (2020)

15. Reis, A. C., Kolvenbach, B. A., Nunes, O. C. \& Corvini, P. F. Biodegradation of antibiotics: The new resistance determinants-part I. N. Biotechnol. 54, 34-51 (2020).

16. Cai, J. et al. A novel strategy for enhancing anaerobic biodegradation of an anthraquinone dye reactive blue 19 with resuscitation-promoting factors. Che mosphere 263, 127922 (2021).

17. Arabkhani, P. \& Asfaram, A. Development of a novel three-dimensional magnetic polymer aerogel as an efficient adsorbent for malachite green removal. J. Hazard. Mater. 384, 121394 (2020)

18. Arabkhani, P., Asfaram, A. \& Ateia, M. Easy-to-prepare graphene oxide/sodium montmorillonite polymer nanocomposite with enhanced adsorption performance. J. Water Process Eng. 38, 101651 (2020).

19. Ali, S. I. et al. Estimation of asphaltene adsorption on $\mathrm{MgO}$ nanoparticles using ensemble learning. Chemom. Intell. Lab. Syst. 208, 104220 (2021).

20. Jacob, J. J., Varalakshmi, R., Gargi, S., Jayasri, M. A. \& Suthindhiran, K. Removal of $\mathrm{Cr}$ (III) and $\mathrm{Ni}$ (II) from tannery effluent using calcium carbonate coated bacterial magnetosomes. NPJ Clean. Water 1, 1-10 (2018).
21. Sharifpour, E. et al. Modeling and optimization of ultrasound-assisted high-performance adsorption of Basic Fuchsin by starch-capped zinc selenide nanoparticles/AC as a novel composite using response surface methodology. Int. J. Biol. Macromol. 152, 913-921 (2020).

22. Sivalingam, S. \& Sen, S. Rice husk ash derived nanocrystalline ZSM-5 for highly efficient removal of a toxic textile dye. J. Mater. Res. Technol. 9, 14853-14864 (2020).

23. Abd Hamid, S. et al. Role of clay-based membrane for removal of copper from aqueous solution. J. Saudi Chem. Soc. 24, 785-798 (2020).

24. Arabkhani, P., Javadian, H., Asfaram, A. \& Ateia, M. Decorating graphene oxide with zeolitic imidazolate framework (ZIF-8) and pseudo-boehmite offers ultrahigh adsorption capacity of diclofenac in hospital effluents. Chemosphere 271, 129610 (2021)

25. Wani, A. A. et al. Graphene-supported organic-inorganic layered double hydroxides and their environmental applications: A review. J. Cleaner Prod. 122980 (2020).

26. Nebol'sin, V. A., Galstyan, V., \& Silina, Y. E. Graphene oxide and its chemical nature: Multi-stage interactions between the oxygen and graphene. Surf. Interfaces. 100763 (2020).

27. Karimi-Maleh, $\mathrm{H}$. et al. The role of magnetite/graphene oxide nano-composite as a high-efficiency adsorbent for removal of phenazopyridine residues from water samples, an experimental/theoretical investigation. J. Mol. Liq. 298, 112040 (2020).

28. Bezerra de Araujo, C. M. et al. Adsorptive removal of dye from real textile wastewater using graphene oxide produced via modifications of hummers method. Chem. Eng. Commun. 206, 1375-1387 (2019).

29. Huang, H., Zhang, J., Jiang, L. \& Zang, Z. Preparation of cubic $\mathrm{Cu}_{2} \mathrm{O}$ nanoparticles wrapped by reduced graphene oxide for the efficient removal of rhodamine $\mathrm{B}$. J. Alloy. Compd. 718, 112-115 (2017).

30. Dastkhoon, M., Ghaedi, M., Asfaram, A. \& Dil, E. A. Comparative study of ability of sonochemistry combined $\mathrm{ZnS}$ : Ni nanoparticles-loaded activated carbon in reductive of organic pollutants from environmental water samples. Polyhedron 180, 114341 (2020).

31. Karimi, R., Yousefi, F., Ghaedi, M. \& Dashtian, K. Back propagation artificial neural network and central composite design modeling of operational parameter impact for sunset yellow and azur (II) adsorption onto MWCNT and MWCNT-PdNPs: Isotherm and kinetic study. Chemom. Intell. Lab. Syst. 159, 127-137 (2016).

32. Bernardi, S. et al. Ultrasound: A suitable technology to improve the extraction and techno-functional properties of vegetable food proteins. Plant Foods Hum. Nutr. 76, 1-11 (2021)

33. Dehane, A., Merouani, S. \& Hamdaoui, O . Effect of carbon tetrachloride ( $\mathrm{CCl} 4)$ sonochemistry on the size of active bubbles for the production of reactive oxygen and chlorine species in acoustic cavitation field. Chem. Eng. J 426, 130251 (2021).

34. Pereira, L. M. S., Milan, T. M. \& Tapia-Blácido, D. R. Using Response Surface Methodology (RSM) to optimize $2 \mathrm{G}$ bioethanol production: A review. Biomass. Bioener. 151, 106166 (2021).

35. Sachaniya, B. K., Gosai, H. B., Panseriya, H. Z. \& Dave, B. P. Bioengineering for multiple PAHs degradation for contaminated sediments: Response surface methodology (RSM) and artificial neural network (ANN). Chemom. Intell. Lab. Syst. 202, 104033 (2020).

36. Deng, J. H. et al. Simultaneous removal of $\mathrm{Cd}$ (II) and ionic dyes from aqueous solution using magnetic graphene oxide nanocomposite as an adsorbent. Chem. Eng. J. 226, 189-200 (2013).

37. Dikin, D. A. et al. Preparation and characterization of graphene oxide paper. Nature 448, 457-460 (2007).

38. Shojaei, S., Shojaei, S., Nouri, A. \& Baharinikoo, L. Application of chemometrics for modeling and optimization of ultrasound-assisted dispersive liquid-liquid microextraction for the simultaneous determination of dyes. npj. Clean. Water $\mathbf{4}$, 1-8 (2021).

39. Shojaei, S., Nouri, A., Baharinikoo, L., Farahani, M. D. \& Shojaei, S. Removal of the hazardous dyes through adsorption over nanozeolite-X: Simultaneous model, design and analysis of experiments. Polyhedron 196, 114995 (2021).

40. Shojaei, S. et al. Application of Taguchi method and response surface methodology into the removal of malachite green and auramine-O by $\mathrm{NaX}$ nanozeolites. Sci. Rep. 11, 1-13 (2021).

41. Pourabadeh, A., Baharinikoo, L., Nouri, A., Mehdizadeh, B. \& Shojaei, S. The optimisation of operating parameters of dye removal: application of designs of experiments. Int. J. Environ. Anal. Chem. 1-10 (2019).

42. Tang, X., Ran, G., Li, J., Zhang, Z. \& Xiang, C. Extremely efficient and rapidly adsorb methylene blue using porous adsorbent prepared from waste paper: Kinetics and equilibrium studies. J. Hazard. Mater. 402, 123579 (2021).

43. Pytlakowska, K. et al. Determination of heavy metal ions by energy dispersive $\mathrm{X}$-ray fluorescence spectrometry using reduced graphene oxide decorated with 
molybdenum disulfide as solid adsorbent. Spectrochim. Acta. Part B. 167, 105846 (2020).

44. Duhan, M. \& Kaur, R. Nano-structured polyaniline as a potential adsorbent for Methylene blue dye removal from effluent. J. Compos. Sci. 5, 7 (2021).

45. Shabaan, O. A., Jahin, H. S. \& Mohamed, G. G. Removal of anionic and cationic dyes from wastewater by adsorption using multiwall carbon nanotubes. Arab. J. Chem. 13, 4797-4810 (2020).

46. Pérez-Ramírez, E. E. et al. One-and two-dimensional carbon nanomaterials as adsorbents of cationic and anionic dyes from aqueous solutions. Carbon Lett. 29 , 155-166 (2019)

47. Naddeo, V. et al. Removal of contaminants of emerging concern from real wastewater by an innovative hybrid membrane process-UltraSound, Adsorption, and Membrane ultrafiltration (USAMe ${ }^{\circledast}$ ). Ultrason. Sonochem. 68, 105237 (2020).

48. Özyonar, F., Gökkuş, Ö. \& Sabuni, M. Removal of disperse and reactive dyes from aqueous solutions using ultrasound-assisted electrocoagulation. Chemosphere 258, 127325 (2020).

49. Sadegh, N., Asfaram, A., Javadian, H., Haddadi, H. \& Sharifpour, E. Ultrasoundassisted solid phase microextraction-HPLC method based on $\mathrm{Fe}_{3} \mathrm{O}_{4} @ \mathrm{SiO}_{2}-\mathrm{NH}_{2}-$ molecularly imprinted polymer magnetic nano-sorbent for rapid and efficient extraction of harmaline from Peganum harmala extract. J. Chromatogr. B 1171 , 122640 (2021).

50. Khomeyrani, S. F. N., Azqhandi, M. H. A. \& Ghalami-Choobar, B. Rapid and efficient ultrasonic assisted adsorption of PNP onto LDH-GO-CNTs: ANFIS, GRNN and RSM modeling, optimization, isotherm, kinetic, and thermodynamic study. J. Mol. Liq. 333, 115917 (2021).

51. Liu, Y. et al. Graphene oxides cross-linked with hyperbranched polyethylenimines: preparation, characterization and their potential as recyclable and highly efficient adsorption materials for lead (II) ions. Chem. Eng. J. 285, 698-708 (2016).

52. Shoushtarian, F., Moghaddam, M. R. A. \& Kowsari, E. Efficient regeneration/reuse of graphene oxide as a nanoadsorbent for removing basic Red 46 from aqueous solutions. J. Mol. Liq. 312, 113386 (2020).

53. Chen, J. et al. One-pot photochemical synthesis of ultrathin Au nanocrystals on co-reduced graphene oxide and its application. J. Colloid Interface Sci. 383, 140-147 (2012)

54. Maged, A. et al. Enhanced interlayer trapping of $\mathrm{Pb}$ (II) ions within kaolinite layers: intercalation, characterization, and sorption studies. Environ. Sci. Pollut. Res. 27, 1870-1887 (2020)

55. Maged, A. et al. New mechanistic insight into rapid adsorption of pharmaceuticals from water utilizing activated biochar. Environ. Res. 202, 111693 (2021).

56. Lagergren, S. K. About the theory of so-called adsorption of soluble substances. Sven. Vetenskapsakad. Handingarl 24, 1-39 (1898).

57. Blanchard, G., Maunaye, M. \& Martin, G. Removal of heavy metals from waters by means of natural zeolites. Water Res. 18, 1501-1507 (1984).

58. Ho, Y. S. \& McKay, G. Pseudo-second order model for sorption processes. Process Biochem. 34, 451-465 (1999).

\section{ACKNOWLEDGEMENTS}

This research was supported by University of Tehran and Natural Science Foundation of Shandong Province General Program (ZR2020ME226).

\section{AUTHOR CONTRIBUTIONS}

Si.S. conceived and planned the experiments. Sa.S. and Si.S. carried out the experiments. J.Y. critical revision of the article, kinetic and thermodynamic analysis. Sa.S and J.Y. critical revision of the article, technical checking, validation and programming language checking. All authors discussed the results and contributed to the final manuscript.

\section{COMPETING INTERESTS}

The authors declare no competing interests.

\section{ADDITIONAL INFORMATION}

Supplementary information The online version contains supplementary materia available at https://doi.org/10.1038/s41545-022-00148-3.

Correspondence and requests for materials should be addressed to Siroos Shojaei.

Reprints and permission information is available at http://www.nature.com/ reprints

Publisher's note Springer Nature remains neutral with regard to jurisdictional claims in published maps and institutional affiliations.

Open Access This article is licensed under a Creative Commons Attribution 4.0 International License, which permits use, sharing, adaptation, distribution and reproduction in any medium or format, as long as you give appropriate credit to the original author(s) and the source, provide a link to the Creative Commons license, and indicate if changes were made. The images or other third party material in this article are included in the article's Creative Commons license, unless indicated otherwise in a credit line to the material. If material is not included in the article's Creative Commons license and your intended use is not permitted by statutory regulation or exceeds the permitted use, you will need to obtain permission directly from the copyright holder. To view a copy of this license, visit http://creativecommons. org/licenses/by/4.0/

(c) The Author(s) 2022 